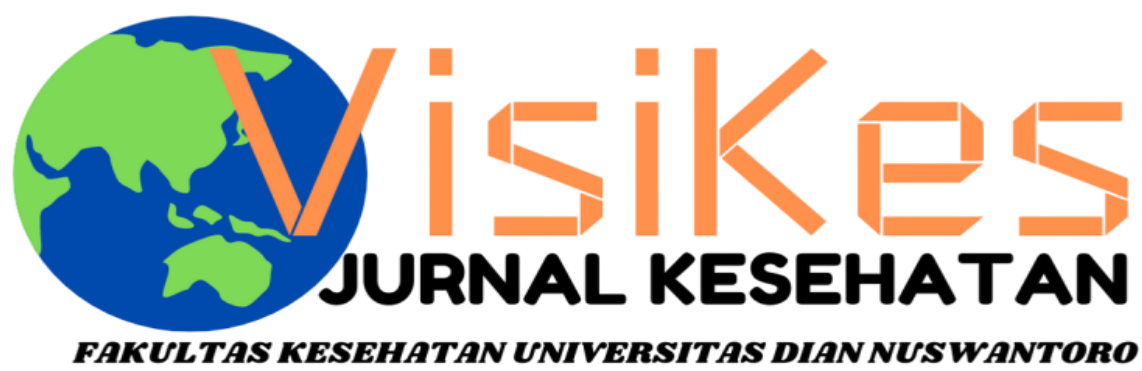

ISSN 1412-3746

FAKULTAS KESEHATAN UNIVERSITAS DIAN NUSWANTORO

Persepsi Mahasiswa Keperawatan Tentang Eskalasi Tenaga Perawat

Rendi Ariyanto Sinanto', Vivi Retno Intening ${ }^{2}$

Risiko kesehatan $\mathrm{Pb}$ dan $\mathrm{Hg}$ pada sayuran di desa Kopeng Kabupaten Semarang

Indira Casheila Anindityo ${ }^{1}$, Nur Endah Wahyuningsih ${ }^{2}$, Yusniar Hanani Darundiati ${ }^{3}$

Analisis Pelaksanaan Program Indonesia Sehat Dengan Pendekatan Keluarga (Pispk) Dalam Capaian Indeks Keluarga

Sehat Di Kabupaten Brebes Tahun 2020 Studi Pada Puskesmas Kluwut Kabupaten Brebes

Rizky Aprilianti Lestari ${ }^{1}$ dr. Antono Suryoputro ${ }^{1}$ Dr. dr. Apoina Kartini. M. Kes ${ }^{1}$

Disiplin Keselamatan dan Kesehatan Kerja melalui pemakaian alat pelindung diri di laboratorium kimia PT Sucofindo

Jakarta

Susan Endah Kartikasari ${ }^{1}$, Tatan Sukwika ${ }^{2}$

Perbedaan Pengetahuan Anemia dan Tablet Tambah Darah (TTD) Sebelum dan Sesudah Pendidikan Kesehatan Melalui

Media Video dan Aplikasi Quizlet

Devita Sari ${ }^{1}$, Gisely Vionalita ${ }^{2}$

Tingkat Pengetahuan Dan Perilaku Mahasiswi Mengenai Legalitas Dan Keamanan Kosmetik

Hani Sri Fitriani, Rizki Siti Nurfitria

Evaluasi Manajemen Dokumen Rekam Medis Di Filing Aktif Rumah Sakit Swasta Kabupaten Semarang

Bobby Anggara Laksana Putra ${ }^{1}$, Retno Astuti Setjaningsih ${ }^{2}$

Tingkat Pengetahuan Gizi Seimbang dan Profil Kesehatan Sopir Bus Antar Kota

Vilda Ana Veria Setyawati ${ }^{1}$, Bayu Yoni Setyo Nugroho ${ }^{1}$

Pengaruh Pengetahuan Dan Motivasi Kerja Terhadap Penerapan Early Warning Score System Di Rsup H Adam Malik Ita Riahna Pinem ${ }^{1}$, Zulfendri', Siti Saidah Nasution ${ }^{3}$

Analisis Penelusuran Masker Sebagai Protokol Kesehatan Saat Pandemi Covid-19 Di Indonesia: Studi Google Trends Ully Febra Kusuma ${ }^{1}$, Nurunnisa Arsyad ${ }^{2}$, Melissa Shalimar Lavinia ${ }^{3}$, Selvia Rahayu ${ }^{4}$, M. Khairul Kahfi , Rizma Adllia Syakurah ${ }^{6}$ Perilaku Hidup Bersih Dan Sehat (Phbs) Dengan Kejadian Sakit Pada Siswa Sekolah Dasar Di Kabupaten Banyumas Windri Lesmana Rubai ${ }^{1}$, Pramesthi Widya Hapsari', Katri Andirini Surijati ${ }^{3}$

Identifikasi Risiko Ganguan Muskuloskletal Pada Pekerja Percetakan Dengan Metode Nordic Body Map

Octavianus Hutapea ${ }^{1}$, Moch.Sahri', Rustam Basuki ${ }^{3}$

Literatur review: Implementasi Bauran Pemasaran 7P Terhadap Tingkat Kepuasan Pasien Di Rumah Sakit

Desi Natalia Marpaung ${ }^{1}$ Ernawaty $^{2}$ Diansanto Prayoga ${ }^{3}$ Syifa'ul Lailiyah $^{4}$

Kelengkapan Informasi Medis Untuk Mendukung Kodefikasi Penyakit Jantung Guna Mewujudkan Kualitas Data Informasi Medis Di Rumah Sakit Islam Sultan Agung Semarang

Dyah Ernawati ${ }^{1}$, Ratna Rifatul Ulya ${ }^{2}$, Arif Kurniadi ${ }^{3}$

Kajian Faktor Kendala Dokter Tidak Menggunakan Aplikasi Wifi Tb Di Kota Semarang

Arif Kurniadi', Evina Widianawati2, Dyah Ernawati ${ }^{3}$

Analisis Pelaksanaan Program Penanggulangan Tuberkulosis Paru Di Puskesmas Purwoyoso Kota Semarang

Nahari Ratu Cempaka Wilis ${ }^{1}$ Hardi Warsono ${ }^{2}$ M. Sakundarno Adi ${ }^{3}$

Hubungan Penggunaan Alat Pelindung Diri (Apd) Dengan Kadar Sgot Dan Sgpt Dalam Darah Pada Petani Padi

Iga Maliga, Rafi'ah

Faktor Risiko Kejadian Stunting Pada Balita di Wilayah Kerja Puskesmas Pandan Kabupaten Sintang

${ }^{1}$ Agustini Elisabet, ${ }^{2}$ Elvi Juliansyah

Peran Suami Dan Petugas Kesehatan Dengan Deteksi Dini Kanker Serviks

Christina Leasa, ${ }^{1}$ Mariene Wiwin Dolang

Analisis Penerapan Protokol Kesehatan terhadap Tingkat Kepatuhan Pada Pekerja informal Selama Pandemi Covid-19

MG Catur Yuantari ${ }^{1}$, Enny Rachmani ${ }^{2}$, Eti Rimawati ${ }^{1}$, Sri Handayani ${ }^{1}$, Edi Jaya Kusuma ${ }^{2}$

Peran Pengawas Minum Obat Dan Pendampingan Berobat Ulang Dengan Keberhasilan Pengobatan Tb Paru

Taswin $^{\left.1^{*}\right)}$, (zan $^{1)}$, Wahyuddin $^{1)}$, Dahmar ${ }^{1)}$

Faktor Determinan Sosial Dan Gambaran Kejadian Post Traumatic Syndrome Disorder (Ptsd) Pasca Banjir Di Dki Jakarta

Dan Bekasi Tahun 2020

Thresya Febrianti ${ }^{1}$, Nurfadhillah ${ }^{2}$, Mitha Nurhjanah ${ }^{3}$, Tiara Kautsa Aliefya ${ }^{4}$

Perbedaan Pola Makan Pada Balita Stunting Dan Tidak Stunting Di Kecamatan Teon Nila Serua (Tns) Kabupaten Maluku Tengah

Trixie Leunupun ${ }^{1}$, Ani Margawati' ${ }^{2}$ Annastasia Ediati ${ }^{3}$

Gambaran Pengelolaan Rekam Medis Rawat Inap Di Rsud Syekh Yusuf Kab. Gowa Tahun 2019

Zilfadhilah Arranury*, Surahmawati, Muhammad Rusmin, Tri Addya Karini, Dian Rezki Wijaya, Ranti Ekasari, Jihan Sulfitri

Analisis Risiko Kesehatan dalam Pemanfaatan Kemball Limbah Sludge Industri Makanan PT. X

Sri Slamet Mulyati ${ }^{1}$, Fajar Sihite ${ }^{2}$ 


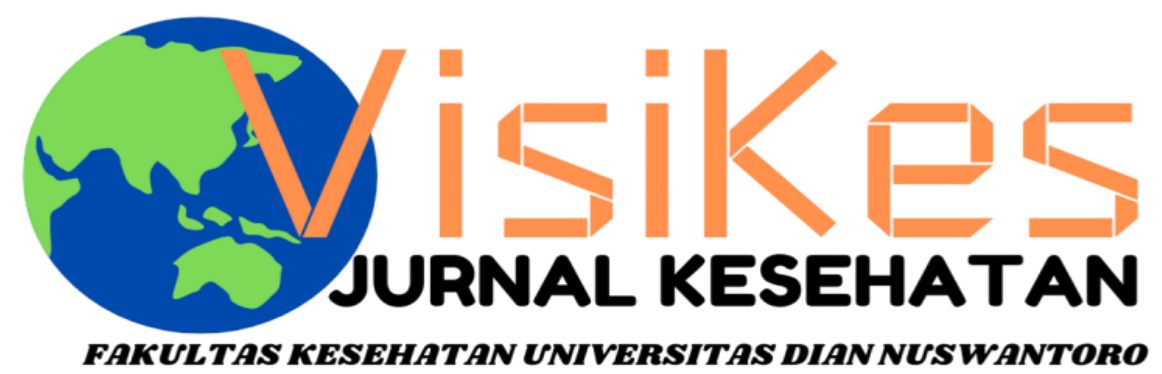

Volume 20, Nomor 1, April 2021

\section{Ketua Redaksi}

Dr. Drs. Slamet Isworo, M.Kes

\section{Penyunting}

Enny Rachmani, SKM, M.Kom, Ph.D

Fitria Wulandari, SKM, M.Kes

\section{Sekretariat}

Lice Sabata, SKM

Desain dan Layout

Puput Nur Fajri, SKM

\section{Alamat Redaksi}

Fakultas Kesehatan Universitas Dian Nuswantoro Jl. Nakula I No. 5-11 Semarang Telp/fax. (024) 3549948

email : visikes@fkes.dinus.ac.id

website $\quad$ : http://publikasi.dinus.ac.id/index.php/visikes/index

VisiKes diterbitkan mulai Maret 2002

Oleh Fakultas Kesehatan Universitas Dian Nuswantoro 


\title{
Identifikasi Risiko Ganguan Muskuloskletal Pada Pekerja Percetakan Dengan Metode Nordic Body Map
}

\author{
Octavianus Hutapea ${ }^{1}$, Moch.Sahri², Rustam Basuki ${ }^{3}$ \\ 1,2Prodi Keselamatan dan Kesehatan Kerja Universitas Nahdlatul Ulama Surabaya \\ ${ }^{3}$ Unit Pelaksanaan Teknis Kesehatan Keselamatan Kerja, Surabaya \\ Email: sahrimoses@unusa.ac.id, octavianus_hutapea@unusa.ac.id
}

\begin{abstract}
An increase in the amount of production in the printing industry will positively impact economic and social aspects. Economic and social aspects that can be directly felt include the increase in individual income and employment in the printing industry sector. Apart from having a positive impact, this also has a negative impact, especially on the health and protection aspects of workers related to occupational safety and health. The type of work in the printing industry is one that has a risk of musculoskeletal disorders. This study aims to determine the prevalence of complaints of musculoskeletal disorders among workers in the printing industry. The method used is a survey using a Nordic body map using a questionnaire. The results showed that $8 \%$ of workers experienced complaints on the musculoskeletal system. Complaints of disorders of the skeletal muscles experienced by workers complained of back pain (32\%), complained of pain in the forearm and right shoulder (28\%), complained of pain in the left shoulder, back and right upper arm (24\%), complained pain in the neck, left upper and lower arm, right calf and left toe (20\%).
\end{abstract}

Keywords: nordic body map, musculoskeletal complaints, printing industry

\section{PENDAHULUAN}

Pertumbuhan industri manufaktur mulai

dari skala sedang pada tahun 2019 mengalami kenaikan sebesar 4,01 persen dari tahun sebelumnya. Kenaikan ini disebabkan karena naiknya produksi industri percetakan dan resproduksi media tekaman sebesar 19,58 persen ${ }^{(1)}$. Peningkatan jumlah produksi pada industri percetakan secara posisitif akan berdampak pada dua aspek yaitu ekonomi dan sosial. Aspek ekonomi dan sosial secara langsung dapat dirasakan antara lain peningkatan pendapatan individu dan penyerapan tenaga kerja pada sektor industri percetakan. Selain berdampak posistif, hal ini juga mempunyai dampak negatif terutama pada aspek kesehatan dan perlindungan pekerja terkait dengan keselamatan dan Kesehatan kerja. Jenis pekerjaan pada industri percetakan merupakan salah satu pekerjaan yang mempunyai risiko terhadap gangguan musculoskeletal.

Keluhan muskuloskeletal merupakan keluhan yang ada pada otot skeletal yang dirasakan oleh individu mulai dari keluhan tidak sakit sampai sangat sakit ${ }^{(2)}$. Penerapan ergonomi ditempat kerja merupakan salah satu cara untuk meningkatkan produktifitas karena dengan penerapan ergonomi dengan baik maka pekerjaan akan menjadi lebih cepat, lebih mudah dan menghasilkan produk yang bermutu karena dilakukan secara sistematis. Dalam ilmu ergonomi juga diatur mengenai stasiun kerja agar sesuai dengan ukuran dimensi tubuh pekerja sehingga pekerja dapat merasa nyaman dan aman dalam melakukan pekerjaanya. Musculoskeletal merupakan salah satu risiko gangguan Kesehatan akibat factor ergonomi. Risiko gangguan Kesehatan berupa 
gangguan musculoskeletal dapat terjadi pada individu sebagai akibat dari sikap tubuh yang tidak normal saat melakukan pekerjaan seperti membungkuk, menjangkau, berdiri dan lain-lain. Posisi kerja yang tidak normal tersebut masih banyak ditemui pada pekerjaan percetakan baik pada bagian produksi maupun pada bagian administrasi.

Penelitian yang dilakukan Ari Ashari dkk pada industri percetakan di kota Makasar didapatkan hasil 78,8 persen pekerja mengalami keluhan pada system musculoskeletal (3). Berdasarkan penelitian yang dilakukan oleh Foong May Chi, Prevalensi gejala gangguan musculoskeletal pada pekerja percetakan di Malaysia sebesar 79,6 persen dan 48 persen keluhan mayoritas yang dirasakan sakit pada tulang punggung (4). Penelitian yang dilakukan oleh Shankar dari negara India pada industry percetakan menunjukkan bahwa 62,5 persen pekerja rentan terhadap gejala musculoskeleta pada punggung bawah 75,1 persen, bahu 66,2 persen, lutut 58,7 persen dan pergelangan kaki 55,6 persen ${ }^{(5)}$.

Berdasarkan latar belakang tersebut peneliti tertarik untuk melakukan studi terkait keluhan gangguan musculoskeletal yang dialami oleh pekerja sektor percetakan. Alasan pemilihan objek penelitian pada sektor percetakan yaitu industri percetakan disurabaya merupakan salah satu sector industry informal yang banyak ditemui dan perlu mendapatkan perhatian tertkait Kesehatan dan keselamatan kerjanya. Hasil penelitian ini diharapkan dapat memberikan masukan kepada pemangku kepentingan yang mempunyai peran untuk membina K3 pada sector informal seperti pos Upaya Kesehatan kerja. Pos upaya Kesehatan kerja merupakan tempat untuk upaya kesehatan yang berbasis pada masyarakat pekerja terutama pekerja sektor informal yang dikelola dan diselenggarakan dari, oleh, untuk dan bersama masyarakat pekerja melalui pelayanan kesehatan dengan pendekatan utama promosi dan pencegahan. Upaya pengobatan dan rehabilitatif juga ada dalam layanan Kesehatan kerja namun pelaksanaannya lebih terbatas ${ }^{(6)}$.

\section{METODE PENELITIAN}

Studi ini dilakukan di salah satu sektor informal industry percetakan yang ada dikota Surabaya. Sampel penelitian berjumlah 25 orang dengan berbagai macam unit kerja dan posisi bekerja. Penelitian ini diawal dengan melakukan observasi lapangan dengan melihat jenis pekerjaan dan posisi kerja yang dilakukan oleh pekerja dalam kebiasaan sehari-hari. Dari observasi ditemukan adanya berbagai macam jenis pekerjaan yang berisiko untuk mengalamai gangguan musculoskeletal antara lain sortir, bagian gudang, administrasi, Finishing dan Operator. Posisi kerja dalam melakukan kegiatan pekerjaan juga sangat bervariasi ada yang duduk, berdiri dan posisi kombinsi duduk dan berdiri.

Variabel dalam penelitian ini yaitu posisi kerja, unit kerja, kebiasaan mengangkat beban dan pekerjaan berulang. Penilaian risiko gangguan musculoskeletal dalam studi ini menggunakan metode Nordic Body Map dengan intrumen berupa kuesioner. 
Selanjutnya data di analisis dengan perhitungan nilai risiko sesuai dengan panduan penggunaan metode Nordic body map. Penilaian dilakukan pada setiap individu dengan skala likert yang telah di tetapkan. Skala tersebut berupa keterangan yang ada di lembar kuesioner yang terdiri dari
TIDAK SAKIT dengan skor 1, AGAK SAKIT dengan skor 2, SAKIT dengan skor 3, dan SANGAT SAKIT dengan skor 4. Hasil penilaian kemudian dijumlahkan dan nilainya disesuaiakan dengan tabel nilai risiko (7) sebagai berikut:

Tabel 1 : Kategori Tingkat Risiko MSDs Berdasarkan Total Skor Individu

\begin{tabular}{cccl}
\hline Skala & Total Skor & Tingkat Risiko & \multicolumn{1}{c}{ Tindakan Perbaikan } \\
\hline $\mathbf{1}$ & $28-49$ & Rendah & Belum diperlukan adanya tindakan perbaikan \\
\hline $\mathbf{2}$ & $50-70$ & Sedang & Mungkin diperlukan tindakan dikemudian hari \\
\hline $\mathbf{3}$ & $71-91$ & Tinggi & Diperlukan tindakan segera \\
\hline $\mathbf{4}$ & $92-112$ & Sangat Tinggi & Diperlukan tindakan menyeluruh sesegera mungkin \\
\hline
\end{tabular}

Pengolahan data dilakukan sengan analisis deskriptif dan disajikan dalam bentuk narasi dan tabulasi untuk mempermudah pemahaman.
HASIL

Penelitian yang dilakukan pada 25 responden karyawan percetakan diperoleh hasil penelitian sebagai berikut:

Tabel 2. Distribusi karakteristik responden diindustri percetakan X 2020

\begin{tabular}{|c|c|c|c|}
\hline Variabel & Kategori & $\mathbf{N}$ & $\%$ \\
\hline \multirow[t]{3}{*}{ Umur } & Remaja (12 - 25) & 6 & 24 \\
\hline & Dewasa (26 - 45) & 16 & 64 \\
\hline & Lansia (> 45) & 3 & 12 \\
\hline \multirow[t]{2}{*}{ Jenis kelamin } & Laki-laki & 15 & 60 \\
\hline & Perempuan & 10 & 40 \\
\hline \multirow[t]{5}{*}{ Bagian } & Gudang & 4 & 16 \\
\hline & Admin & 3 & 12 \\
\hline & Operator produksi & 9 & 36 \\
\hline & Finishing & 7 & 28 \\
\hline & Sortir & 2 & 8 \\
\hline \multirow[t]{2}{*}{ Masa kerja } & $\leq 10$ tahun & 16 & 64 \\
\hline & $>10$ tahun & 9 & 36 \\
\hline \multirow[t]{3}{*}{ Sikap kerja } & Duduk & 5 & 20 \\
\hline & Berdiri & 5 & 20 \\
\hline & Duduk dan berdiri & 15 & 60 \\
\hline \multirow[t]{2}{*}{ Melakukan pekerjaan berulang } & $\mathrm{Ya}$ & 17 & 68 \\
\hline & Tidak & 8 & 32 \\
\hline \multirow[t]{2}{*}{ Posisi tubuh membungkuk } & Ya & 18 & 72 \\
\hline & Tidak & 9 & 36 \\
\hline \multirow[t]{2}{*}{ Mengangkat beban > $10 \mathrm{~kg}$} & Ya & 18 & 72 \\
\hline & Tidak & 7 & 28 \\
\hline \multirow[t]{4}{*}{ Keluhan gangguan musculoskeletal } & Rendah & 23 & 92 \\
\hline & Sedang & 2 & 8 \\
\hline & Tinggi & 0 & 0 \\
\hline & Sangat tinggi & 0 & 0 \\
\hline
\end{tabular}

Pada tabel 2 dapat dilihat bahawa karakteristik responden didominasi oleh usia 
dewasa (26 - 45 tahun) sebanyak 16 orang (64\%), jenis kelamin laki-laki sebanyak 15 orang $(60 \%)$, bekerja pada bagian operator produksi sebanyak 9 orang (36\%), masa kurang dari sepuluh tahun sebanyak 16 orang (64\%), posisi kerja duduk dan berdiri sebanyak 15 orang (60\%), melakukan pekerjaan berulang sebanyak 17 orang
(68\%), posisi tubuh membungkuk sebanyak 18 orang $(68 \%)$, mengangkat beban lebih dari $10 \mathrm{~kg}$ sebanyak 18 orang (72\%) dan keluhan gangguan muskuloskletal pada risiko sedang sebanyak 2 orang (8\%). Distribusi keluhan gangguan musculoskeletal pada pekerja percetakan sebagai berikut:

Tabel 3. Distribusi keluhan Musculoskeletal pada pekerja percetakan

\begin{tabular}{lcccccccc}
\hline & \multicolumn{3}{c}{ Keluhan } & \multicolumn{2}{c}{ Agak sakit } & \multicolumn{2}{c}{ Sakit } & \multicolumn{2}{c}{ Sakit sekali } \\
\cline { 2 - 10 } & $\mathbf{N}$ & $\%$ & $\mathbf{n}$ & $\%$ & $\mathbf{n}$ & $\%$ & $\mathbf{n}$ & $\%$ \\
\hline Sakit/kaku di leher bagian atas & 18 & 72 & 5 & 20 & 1 & 4 & 1 & 4 \\
\hline Sakit/kaku di leher bagian bawah & 20 & 80 & 4 & 16 & 1 & 4 & 0 & 0 \\
\hline Sakit di bahu kiri & 15 & 60 & 4 & 16 & 6 & 24 & 0 & 0 \\
\hline Sakit di bahu kanan & 15 & 60 & 7 & 28 & 3 & 12 & 0 & 0 \\
\hline Sakit pada lengan atas kiri & 18 & 72 & 2 & 8 & 5 & 20 & 0 & 0 \\
\hline Sakit di punggung & 16 & 64 & 6 & 24 & 3 & 12 & 0 & 0 \\
\hline Sakit pada lengan atas kanan & 18 & 72 & 6 & 24 & 1 & 4 & 0 & 0 \\
\hline Sakit pada pinggang & 13 & 52 & 8 & 32 & 4 & 16 & 0 & 0 \\
\hline Sakit pada bokong & 19 & 76 & 4 & 16 & 2 & 8 & 0 & 0 \\
\hline Sakit pada pantat & 22 & 88 & 3 & 12 & 0 & 0 & 0 & 0 \\
\hline Sakit pada siku kiri & 21 & 84 & 3 & 12 & 1 & 4 & 0 & 0 \\
\hline Sakit pada siku kanan & 21 & 84 & 3 & 12 & 1 & 4 & 0 & 0 \\
\hline Sakit pada lengan bawah kiri & 19 & 76 & 5 & 20 & 1 & 4 & 0 & 0 \\
\hline Sakit pada lengan bawah kanan & 18 & 72 & 7 & 28 & 0 & 0 & 0 & 0 \\
\hline Sakit pada pergelangan tangan kiri & 20 & 80 & 3 & 12 & 2 & 8 & 0 & 0 \\
\hline Sakit pada pergelangan tangan kanan & 19 & 76 & 3 & 12 & 3 & 12 & 0 & 0 \\
\hline Sakit pada jari-jari tangan kiri & 22 & 88 & 3 & 12 & 0 & 0 & 0 & 0 \\
\hline Sakit pada jari-jari tangan kanan & 22 & 88 & 3 & 12 & 0 & 0 & 0 & 0 \\
\hline Sakit pada paha kiri & 24 & 96 & 1 & 4 & 0 & 0 & 0 & 0 \\
\hline Sakit pada paha kanan & 24 & 96 & 1 & 4 & 0 & 0 & 0 & 0 \\
\hline Sakit pada lutut kiri & 22 & 88 & 3 & 12 & 0 & 0 & 0 & 0 \\
\hline Sakit pada lutut kanan & 21 & 84 & 4 & 16 & 0 & 0 & 0 & 0 \\
\hline Sakit pada betis kiri & 19 & 76 & 4 & 16 & 1 & 4 & 1 & 4 \\
\hline Sakit pada betis kanan & 19 & 76 & 5 & 20 & 0 & 0 & 1 & 4 \\
\hline Sakit pada pergelangan kaki kiri & 21 & 84 & 3 & 12 & 1 & 4 & 0 & 0 \\
\hline Sakit pada pergelangan kaki kanan & 21 & 84 & 3 & 12 & 1 & 4 & 0 & 0 \\
\hline Sakit pada jari kaki kiri & 19 & 76 & 5 & 20 & 1 & 4 & 0 & 0 \\
\hline Sakit pada jari kaki kanan & 20 & 80 & 4 & 16 & 1 & 4 & 0 & 0
\end{tabular}

Berdasarkan tabel 3 keluhan gangguan musculoskeletal yang dialami oleh para pekerja, sebanyak 8 orang (32\%) mengeluh sakit pada punggung, sebanyak 7 orang (28\%) mengeluh sakit pada lengan bawah dan bahun sebelah kanan, sebanyak 6 orang
(24\%) mengeluh sakit pada bahu kiri, punggung dan lengan atas kanan, sebanyak 5 orang $(20 \%)$ mengeluh sakit pada bagian leher, lengan atas dan bawah sebelah kiri, betis kanan dan jari kaki sebelah kiri.

\section{PEMBAHASAN}


Keluhan gangguan musculoskeletal dapat disebabkan oleh beberapa faktor antara lain pembebanan otot yang berlebihan, pekerjaan yang berulang-ulang, postur kerja yang janggal, usia, masa kerja dan jenis kelamin (2). Peregangan otot berlebih dapat terjadi akibat dari atifitas seperti mengangkat, menarik, mendorong dan menahan beban berat. Berdasarkan hasil penelitian didapatkan hasil bahwa responden melakukan pekerjaan dengan mengangkat beban lebih dari $10 \mathrm{~kg}$ sebanyak $72 \%$. Pekerjaan dengan mengangkat beban secara manual ditemukan bahwa risiko cedera terbesar pada punggung bawah dan keluhan yang dirasakan pada pekerja dengan mengangkat beban secara manual yaitu nyeri pada pinggang dan leher ${ }^{(8)}$.

Pekerjaan dengan aktifitas pengulangan yang tinggi juga dapat menjadi faktor terjadinya gangguan musculoskeletal. Berdasarkan hasil penelitian 68\% pekerja melakukan pekerjaan dengan aktivitas yang berulang. Gerakan berulang baik pada tangan atau kombinasi dengan faktor risiko fisik, nonfisik, dan non-pekerjaan lainnya, berkontribusi terhadap risiko gangguan musculoskeletal pada tangan maupun pada pergelangan tangan ${ }^{(9)}$. Sikap kerja yang tidak alamiah juga dapat meningkatkan risiko gangguan musculoskeletal pada pekerja. Hasil penelitian menunjukkan posisi tubuh yang tidak alamiah yang sering dilakukan oleh pekerja $72 \%$ adalah posisi tubuh membungkuk. Postur tubuh yang tidak alamiah, ekstrem, dan berulang dapat meneyababkan gangguan pada muskuloskeletal dan cedera pada punggung bawah (10). Hasil penelitian yang dilakukan oleh Anita Abd Rahman terdapat hubungan yang signifikan antara posisi tubuh yang tidak alamiah terhadap gangguan musculoskletal (11)(12). Berdasarkan penelitian Evadarianto (2017) didapatkan kesimpulan bahawa Postur kerja yang janggal dapat menyebabkan kejadian keluhan muskuloskeletal. Semakin buruk postur kerja, maka keluhan pada otot skeletal juga semakin tinggi (13). Semakin jauh posisi bagian tubuh dari pusat tubuh, maka semakin tinggi pula resiko terjadinya keluhan musculoskletal (2). Bagian otot pada operator percetakan yang mempunyai risiko cidera yaitu bahu kiri, bahu kanan, lengan atas kiri dan pergelangan tangan (14).

Umur merupakan salah satu penyebab risiko terjadinya gangguan pada sistem musculoskeletal. Dari hasil penelitian 64\% usia pekerja pada kategori usia dewasa. keluhan gangguan musculoskeletalmulai diraskan pada usia ntara 25 - 65 tahun. Keluhan awal pada umumnya dirasakan saat menginjak usia 35 tahun dan keluhan akan meningkat terus seiring dengan bertambahnya usia hal ini karena kekuatan dan ketahan otot mulai menurun sehingga risiko gangguan pada musculoskeletal juga meningkat. Hasil penelitian penunjukkan bahwa terdapat hubungan yang signifikan antara usia dengan risiko gangguan musculoskeletal (15)(11)(5)(16). Hasil penelitian yang dilakukan Bukhori (2010), menunjukkan bahwa terdapat hubungan antara keluhan muskoloskeletal dengan usia, pekerja dengan usia $\geq 35$ tahun memiliki risiko keluhan 
musculoskeletal lebih tinggi dibanding kelompok usia $<35^{(17)}$.

Seiring dengan bertambahnya masa kerja risiko gangguan terhadap sistem musculoskeletal akan semakin meningkat. Data hasil penelitian ini menunjukkan 36\% pekerja mempunyai masa kerja lebih dari 10 tahun. Berdasarkan penelitian yang dillakukan oleh Ria (2018) terdapat hubungan yang signifikan antara masa kerja dengan keluhan gangguan pada system musculoskletal ${ }^{(18)(19)}$. Masa kerja pekerja di hitung mulai dari masuk bekerja sampai dilakukan penelitian. Masa kerja menunjukkan lamanya individu melakukan pekerjaan dengan berbagai macam posisi dan postur kerja selama bekerja diindsutri percetakan. Makin lama masa bekerja individu, maka sering melakukan pekerjaan yang menyebabkan meningkatnya beragai macam risiko Kesehatan salah satunya gangguan pada system musculoskletal.

\section{SIMPULAN DAN SARAN}

Berdasarkan dari penelitian ini dapat disimpulkan bahawa tingkat risiko terhadap gangguan musculoskeletal terdapat 2 responden yang berisiko sedang dan mayoritas masih pada kategori rendah sehingga belum perlu dilakukan tindakan perbaikan namun keluhan sakit pada otot skeletal yang dialami oleh pekerja harus menjadi perhatian agar gangguan terhadap musculoskeletal tidak terjadi. Keluhan gangguan pada otot skeletal yang dialami oleh para pekerja mengeluh sakit pada punggung (32\%), mengeluh sakit pada lengan bawah dan bahun sebelah kanan (28\%), mengeluh sakit pada bahu kiri, punggung dan lengan atas kanan (24\%), mengeluh sakit pada bagian leher, lengan atas dan bawah sebelah kiri, betis kanan dan jari kaki sebelah kiri $(20 \%)$.

Secara umum dari hasil penelitian ini dapat disarankan antara lain mengurangi sikap kerja yang tidak normal seperti membungkuk, menjangkau, memutar dan jongkok dengan cara meletakkan peralatan kerja pada ketinggian atau disekitar tubuh yang mudah dijangkau. Mengurangi beban yang diangkat tidak lebih dari $15 \mathrm{~kg}$ dan jika lebih usahakan mengangkat dengan bantuan alat atau dengan 2 orang. Mengurangi frekuensi gerakan berulang dengan cara mengelompokkan proses sehingga menjadi berurutan, mengurangi posisi berdiri pada saat melakukan pekerjaan dengan cara menyediakan tempat duduk yang dapat disesuaikan dengan meja atau area kerja.

\section{DAFTAR PUSTAKA}

1. Badan Pusat Statistik. Statistik Pertumbuhan Produksi Industri Manufaktur. 2019;(38):1-12.

2. Tarwaka, Bakri SHA. Ergonomi untuk Keselamatan, Kesehatan Kerja dan Produktivitas [Internet]. 2016. 383 p. Available from: http://shadibakri.uniba.ac.id/wpcontent/uploads/2016/03/BukuErgonomi.pdf

3. Ashari A, Naiem MF, Rahim MR. Gambaran Keluhan Gangguan Kesehatan Pada Operator Percetakan Kota Makassar Tahun 2013. 2013;1-10.

4. Chi FM. Prevalence Of Musculoskeletal 
Symptoms And Associated Risk Factors Among Workers In The Printing Industry. Universiti Putra Malaysia; 2012.

5. Shankar $S$, Naveen Kumar $R$, Mohankumar P, Jayaraman S. Prevalence of work-related musculoskeletal injuries among South Indian hand screen-printing workers. Work. 2017;58:163-72.

6. Kementerian Kesehatan RI. Peraturan Menteri Kesehatan RI No 100 tahun 2015 Tentang Pos Upaya Kesehatan Kerja Terintegrasi. 2015;(100):1-44.

7. Tarwaka. Ergonomi Industri, Dasar-Dasar Pengetahuan Ergonomi dan Aplikasi di Tempat Kerja. Solo: Harapan Press Solo; 2010.

8. Chin J, Herlina, Iridiastadi $\mathrm{H}$, Shu-Chiang L, Fadil Persada S. Workload Analysis by Using Nordic Body Map, Borg RPE and NIOSH Manual Lifting Equation Analyses: A Case Study in Sheet Metal Industry. J Phys Conf Ser. 2019;1424(1).

9. Barr AE, Barbe MF, Clark BD. Workrelated musculoskeletal disorders of the hand and wrist: epidemiology, pathophysiology, and sensorimotor changes. J Orthop Sports Phys Ther [Internet]. $2004 \quad$ Oct;34(10):610-27. Available from: https://pubmed.ncbi.nlm.nih.gov/1555270 7

10. Chowdhury SS, Boricha J, Yardi S. Identification of awkward postures that cause discomfort to Liquid Petroleum Gas workers in Mumbai, India. Indian J Occup Environ Med [Internet]. 2012 Jan;16(1):3-
8. Available from: https://pubmed.ncbi.nlm.nih.gov/2311249 9

11. Anita AR, Yazdani A, Hayati KS, Adon MY. Association between awkward posture and musculoskeletal disorders (MSD) among assembly line workers in an automotive industry. Malaysian $\mathrm{J}$ Med Heal Sci. 2014;10(1):23-8.

12. Ezugwu UA, Egba EN, Igweagu PC, Eneje LE, Orji S, Ugwu UC. Awareness of Awkward Posture and Repetitive Motion as Ergonomic Factors Associated With Musculoskeletal Disorders by Health Promotion Professionals. Glob J Health Sci. 2020;12(6):128.

13. Evadarianto N. Postur Kerja Dengan Keluhan Musculoskeletal Disorders Pada Pekerja Manual Handlingbagian Rolling Mill. Indones J Occup Saf Heal. 2017;6(1):97.

14. Wijaya K. Identifikasi Risiko Ergonomi dengan Metode Nordic Body Map Terhadap Pekerja Konveksi Sablon Baju [Internet]. idec.ft.uns.ac.id. Available from: https://idec.ft.uns.ac.id/wpcontent/uploads/2019/05/ID075.pdf

15. Tualeka AR, Jalaludin J, Salesman F, ... Correlation between Age, Working Period and Work-Related Musculoskeletal Complaints with Nordic Body Map among Fishermen [Internet]. Iranian Journal of .... ijph.tums.ac.ir; 2020. Available from: http://ijph.tums.ac.ir/index.php/ijph/article/ view/19928/6714

16. Di K, Lumajang $\mathrm{K}$, Kesehatan B, Masyarakat FK. Kurnia Ardiansyah Akbar 
1 DETERMINANTS OF MUSCULOSKELETAL DISORDERS IN COFFEE Abstract kopi , kegiatan memetik kopi dilakukan Peningkatan produktivitas kopi di pandang varietas dan proses tanam serta juga memiliki peranan kunci . Gangguan. 2020;4(2):3241.

17. Endang Bukhori. Hubungan Faktor Risiko Pekerjaan Dengan Terjadinya Keluhan Musculoskeletal Disorder (MSDs) Pada Tukang Angkat Beban Penambang Emas Di Kecamatan Cilograng Kabupaten Lebak Tahun 2010. Universitas Islam Negeri Syarif Hidayatullah; 2010.

18. Oley RA, Suoth LF, Asrifuddin A.
Hubungan Antara Sikap Kerja dan Masa Kerja dengan Keluhan Musculoskleletal pada Nelayan di Kelurahan Batukota Kecamatan Lembeh Utara Kota Bitung Tahun 2018. J Kesehat Masy [Internet]. 2018;7(5). Available from: https://ejournal.unsrat.ac.id/index.php/kes mas/article/viewFile/22505/22196

19. Helmina, Diani N, Hafifah I. Hubungan Umur, Jenis Kelamin, Masa Kerja dan Kebiasaan Olahraga dengan keluhan Musculoskeletal Disorders (MSDs) pada Perawat. Caring Nurs Jounal [Internet]. 2019;3(1):24. Available from: journal.umbjm.ac.id/index.php/caringnursing 